\title{
Correction to: A meta-measure of performance related to both investors and investments characteristics
}

\author{
Monica Billio ${ }^{1} \cdot$ Bertrand Maillet $^{2,3,4}$ D $\cdot$ Loriana Pelizzon $^{5}$
}

(c) Springer Science+Business Media, LLC, part of Springer Nature 2021

\section{Correction to: Annals of Operations Research https://doi.org/10.1007/s10479-020-03771-w}

This correction is published as acknowledgment was updated to read as "Pelizzon also thanks the Leibniz Institute for Financial Research SAFE for financially sponsoring this research."

Original article has been corrected.

Publisher's Note Springer Nature remains neutral with regard to jurisdictional claims in published maps and institutional affiliations.

The original article can be found online at https://doi.org/10.1007/s10479-020-03771-w.

\section{Bertrand Maillet}

bmaillet@em-lyon.com

Monica Billio

billio@unive.it

Loriana Pelizzon

pelizzon@safe-frankfurt.de

1 Ca' Foscari Univ. and GRETA, Venice, Italy

2 Emlyon Business School (AIM QUANT Research Center), Paris, France

3 Univ. La Reunion, Saint-Denis, France

4 Variances, Paris, France

5 Leibniz Institute SAFE and Goethe University of Frankfurt, Frankfurt, Germany 